\title{
Gabriele-Aldo Bertozzi, George Sand chez moi,
} «Plaisance», anno IV, n. 11

\section{Marco Stupazzoni}

\section{(2) OpenEdition}

1 Journals

\section{Edizione digitale}

URL: http://journals.openedition.org/studifrancesi/8314

DOI: $10.4000 /$ studifrancesi.8314

ISSN: 2421-5856

\section{Editore}

Rosenberg \& Sellier

\section{Edizione cartacea}

Data di pubblicazione: 1 mai 2009

Paginazione: 197

ISSN: 0039-2944

\section{Notizia bibliografica digitale}

Marco Stupazzoni, «Gabriele-Aldo Bertozzi, George Sand chez moi, «Plaisance», anno IV, n. $11 »$, Studi

Francesi [Online], 157 (LIII | I) | 2009, online dal 30 novembre 2015, consultato il 12 janvier 2021. URL: http://journals.openedition.org/studifrancesi/8314 ; DOI: https://doi.org/10.4000/studifrancesi.8314

Questo documento è stato generato automaticamente il 12 janvier 2021.

\section{(c) (i) (9)}

Studi Francesi è distribuita con Licenza Creative Commons Attribuzione - Non commerciale - Non opere derivate 4.0 Internazionale. 


\title{
Gabriele-Aldo Bertozzi, George Sand chez moi, «Plaisance», anno IV, n. 11
}

\author{
Marco Stupazzoni
}

\section{NOTIZIA}

GABRIELE-ALDO BERTOZZI, George Sand chez moi, «Plaisance», anno IV, n. 11, 2007,

pp. 141-147.

1 Nell'edizione del 1888 dei Poètes maudits - piccola ed immensa galleria di poeti che hanno determinato la nascita della letteratura moderna - Verlaine include, tra i sei autori citati in questa raccolta antologica, Marceline Desbordes-Valmore ed indica, tra le «seules femmes de génie set de talent» del XIX secolo, il nome di George Sand. Il giudizio di Verlaine, fondato unicamente sull'ammirazione per il genio e per il talento che egli riconosce a queste due "femmes-artistes", induce Bertozzi a soffermarsi con una certa attenzione sui legami tra la scrittrice e la poetessa, il cui primo e unico contatto, in forma epistolare, avvenne nel febbraio $1835 \mathrm{su}$ pressante invito dell'attrice Marie Dorval, intima amica di entrambe. Siamo di fronte, osserva l'autore, a due donne, a due artiste «si différentes, comme l'a dit Verlaine, par génération, culture et sensibilité; l'une rêve et invente l'aventure, l'autre l'a vécue sur sa peau, exorcisant de la sorte ce spleen caractéristique du siècle. Dans sa révolution, dans son instabilité, George Sand “n'excite que le désespoir”, Marceline sait au contraire que la première révolution doit s'accomplir en nous, et que le monde et le mode de vie de George Sand étaient trop distants des siens pour pouvoir offrir un point de contact» (p. 147). 